\title{
Study of Potential Improvements of Tobacco Curing Process in View of Energy Aspects
}

\author{
K T Jayasinghe and D D Ananda Namal
}

\begin{abstract}
The paper aims at studying the present performance of tobacco curing barns and to investigate the potential improvements in order to modify the existing tobacco barns in the view of energy aspects. The study was done by selecting the different types of tobacco barns which are located in the Matale district area. Temperature variations inside the barn were monitored throughout the complete process in order to find out the heat transfer patterns. The paddy husk charging patterns and the consumption rates, temperature variations inside the furnace were monitored to find out the performance of the furnace. Further the heat distribution ducting system was studied to find out the heat transfer efficiency from the furnace to the barn. The study results found that several improvements are presented and those are discussed in this paper Finally it is expected to reduce the curing period up to 3 days (i.e. half of the existing curing period) in order to achicve an efficient curing system.
\end{abstract}

Key Words: Tobacco, Curing, Barn, Fumace, Ducting, Heat transfer, Paddy husk, Automation

\subsection{Introduction:}

Curing of tobacco leaves is done inside an oven called "Tobacco Barn". Most tobacco curing barns in the country were built several decades ago and almost all of the barns were built by the owners and fueled by wood logs \& barks. Those home made barns are used for bulk curing and the method of heat transfer is indirect. Furnace attached to the barn is also home made ancient type. In 1997, Tobacco Company has developed a grate type paddy husk furnace and then this fumace was introduced to all the tobacco bains in the country by replacing fire wood combustion traditional system. Now all the tobacco barns in the country are operated with paddy husk. It is estimated that the total annual paddy husk consumption for tobacco curing is in the range of $18,000-20,000$ tons and about 1,100 numbers of barns are in operation.

Since there is no such research involved in the areas to improve the furnace or the barns efficiency, the farmers who are involving in this industry have faced several problems such as,

*Uneven heating * Removal of a high quantity of ash

* Obtaining paddy husk * Long curing period and

* Periodical replacement of ducts.

\subsection{Present Curing System}

After picking, the tobacco leaves are dried first before final processing. The leaves are then sorted and strung together in bunches and hung over poles in drying barns.

\subsection{Arrangement of Tobacco Barn}

There is no such special material or techniques used while constructing the barns and normally it looks like a single room building. The walls of the barn are constructed out of engineering bricks or cement blocks and the roof is made out of Galvanized-corrugated sheets. The floor area inside the barn is not cemented or perfectly made. In an average size barn, there are 18 poles; six layers and three per each layer, were laid in equal distances in the barn in order to hang the tobacco bunches. The arrangement of tobacco bunches hanging on poles are given in the Figure 01.

Eng. K T Jnynsinghe, BSC.Eng(Hon), MEng(Energy Techmology), AMIE(Sri Lnikn). Mechanionl Engineer, Energy \& Enwirommental Manngement Centre, National Engineering Resenrch \& Dezelopment Centre.

D D Ananda Namal B Sc. Eng(llno), M Eng (Energy Technology, MIE (Sri Lankn), Deputy General Mannger (Services), National Engineering Research \& Development Centre 


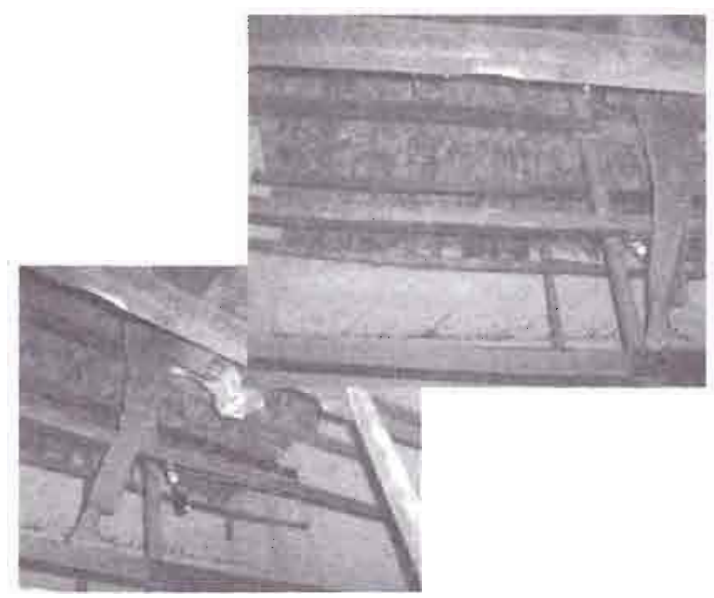

Figure 01-Arrangement of Tobacco BunchesHanging Poles.

Two numbers of $4^{\prime} \times 1^{\prime}$ rectangular openings that closed to the ground level are available on each wall. The sliding doors are available in each opening to control the opening area in order to maintain the heat flow in the barn. Except of these openings $6^{\prime} \times 4^{\prime}$ opening is available on the roof top (called REGIN) with an adjustable door to maintain the inside moisture content.

\section{$2.2 \quad$ Furnace}

The paddy husk burning furnace is attached to the barn outside wall which is the rear side wall of the furnace. The grater consist of 12 numbers of fire clay plates which are placed as a step ladder arrangement and the shape of this grater provides the ventilation for combustion and easy paddy husk flow to the bottom. The top of the grater is used to place the paddy husk charging container. Three numbers of adjustable plates are placed in between grater top level and the paddy husk container bottom level and those can be individually adjusted to feed the paddy husk for the combustion. The un burnt paddy husk and ash particles gets collected to a tray placed at the bottom of the furnace and this level is somewhat below the ground level. Figure 02 shows the furnace arrangement.

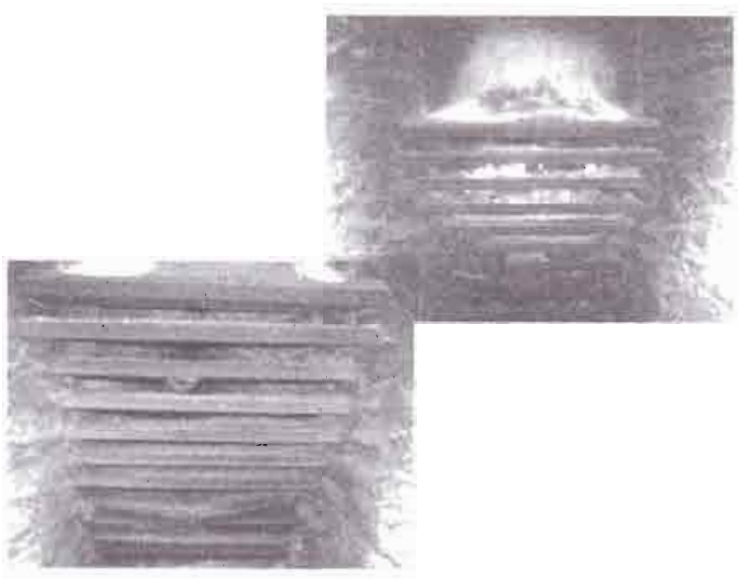

Figure 02-Arrangement of Furnace.

\subsection{Heat Inlet to the Barn}

The heat generated by combusting paddy husk is transferred to the barn via $12^{\prime \prime}$ cast iron pipe which is connected from the furnace and the barn inside. The arrangement of this cast iron pipe is shown in the Figure 03.

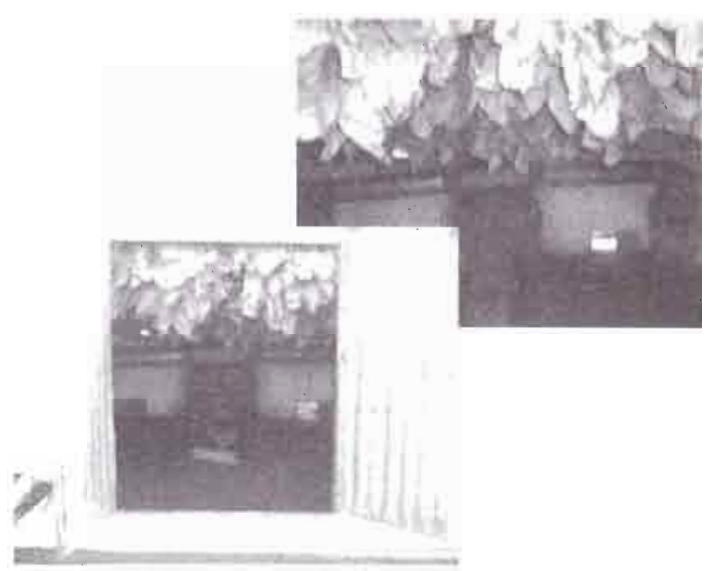

Figure 03. Heat lnlet System to the Barn

\section{$2.4 \quad$ GI. Ducting System (Heat Distributing System)}

The end of the cast iron pipe is connected to the 12 " diameter, galvanized iron ducting system to distribute the heat throughout the barn. Outlet of this ducting system is vertically extended as a chimney and carries away the unused heat from the barn. The heat carried by the ducting system is emitted to the barn as a mode of radiation and then this heat is distributed throughout the barn as a mode of natural convection. 


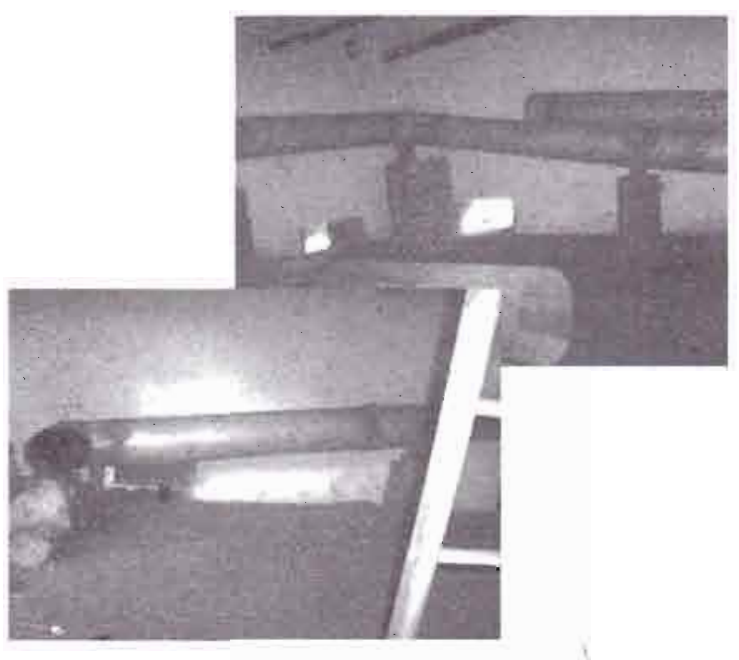

Fig.04 Furnace inside Heat Transfer Ducting System

This ducting system consists of several segments for the purpose of disassembling easily to remove the ash collected in the ducts. The arrangement of the part of the ducting system is shown in Figure 04.

\subsection{Data Analysis}

Temperature variations at eight locations inside the barn were monitored throughout the process during five minutes interval. Also the furnace inlet, outlet and the stack temperatures were monitored in order to find out the furnace performance. The paddy husk charging time \& quantity and ash removing were recorded in order to analyze the combustion performance.

\subsection{Dry Bulb Temperature Variations in the Barn}

The arrangement of temperature measuring locations inside the barn is given below.

* First Layer (Bottom) - Three

Locations

* Third Layer $\quad$ - $\quad$ Single Location

* Fourth Layer - $\quad$ Two Locations

* Sixth Layer (Top) - Two Locations

The analysis is based on the average temperatures in each layer and the variations are shown in Figure 05.

$X$ axis of this graph shows the number of five minutes time intervals during the curing process. According to the graph, this particular batch takes $1500 \times 5$ minutes time for curing process (i.e. closely 5 days).

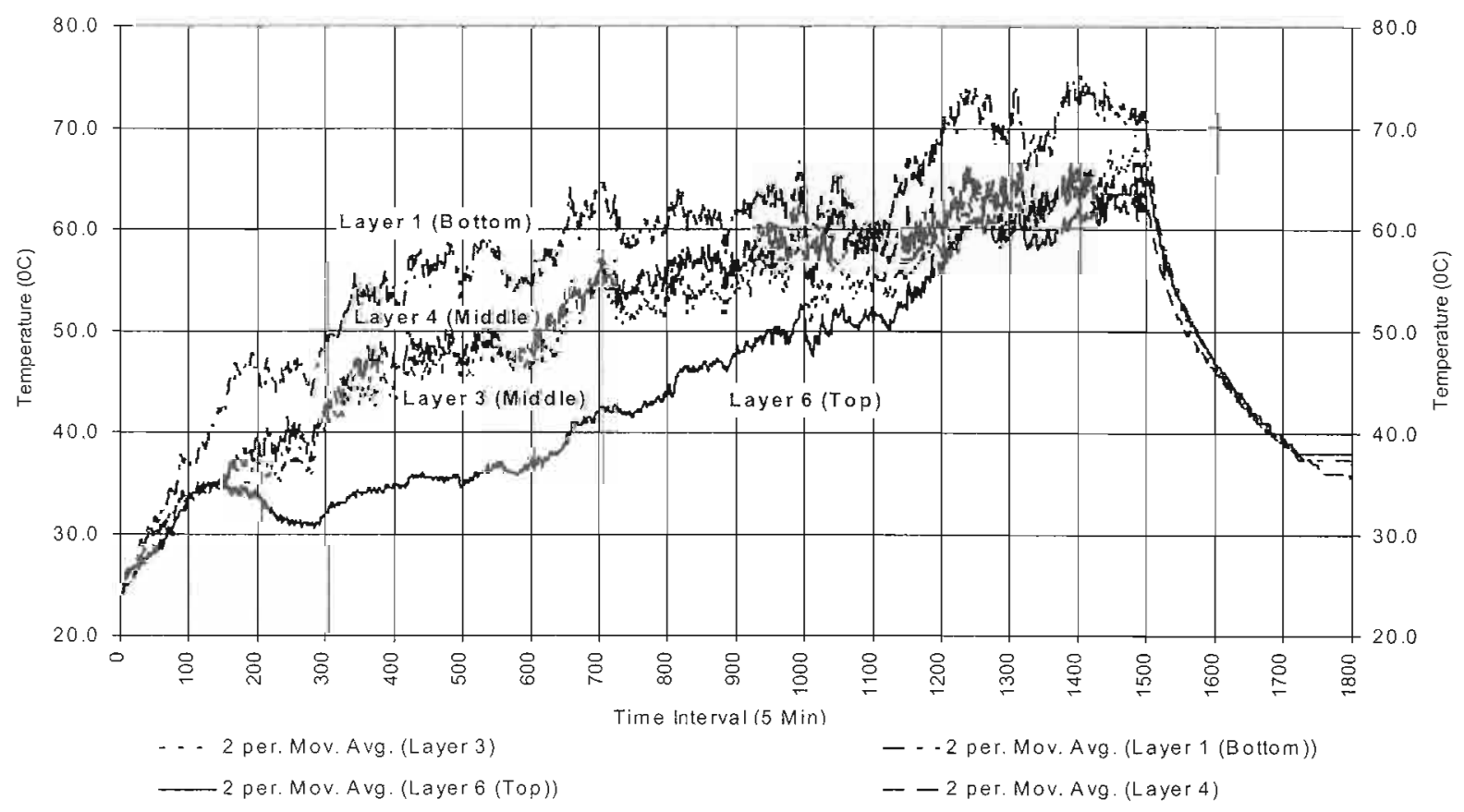

Fig. 05 - Average Temperature Variations in the Barn (Four Layers) 
This graph shows that heat transferring in each layer is very slow from bottom to top layers. For an example, while bottom layer taken one day to reach $50^{\circ} \mathrm{C}$ temperature, third, fourth and top (6th) layers taken 2.1, 2.3 and 3.5 days respectively to reach the same temperature level. This is mainly due to the tight packed of tobacco leaves in each layer and there is no room for heat flow path.

The graph also shows that initially (Before adding heat) the temperature variations of all layers are uniform. This is mainly due to heat generated by barn itself with an effect of solar radiations. Moisture formation inside the barn has increased and flew upwards after adding heat in to the barn. As a result the top layer temperature has gradually dropped (The end of the first day). This is shown in the red line of the graph.

The graph also indicates that the temperature of top layers never reach the maximum temperature of adjacent bottom layer even at the end of the process. As a result the cured leaves are not uniform.

The temperature of the layers suddenly varied within a few degrees and could not be maintained. This mainly depends on the paddy husk feeding rate to the furnace.

\subsection{Heat Transfer to the Barn}

Temperature variation in the furnace (Hearth) and the stack were monitored in the same time intervals as discussed in 3.1. The tabulated results are graphed and shown in the
According to this graph, the average stack temperature has maintained around $200^{\circ} \mathrm{C}$ to $250{ }^{\circ} \mathrm{C}$ during the curing process and the furnace inside temperature has gradually increased around up to $900^{\circ} \mathrm{C}$. This shows that the heat transfer efficiency from the furnace to the barn is around $75 \%$. This reveals that there is no considerable amount of heat waste through the stack.

\subsection{Paddy Husk Consumption}

The paddy husk consumption rate is changed according to the process temperature maintained in the barn. However the total paddy husk consumption to complete a curing process is around $3750 \mathrm{~kg}$. The amount of ash formation is quantified periodically and the estimated total ash formation is around $1000 \mathrm{~kg}$ per batch. That is closely around $25 \%$ of the total paddy husk consumption.

\subsection{Furnace Efficiency}

In practice, the percentage of theoretical ash formation by combusting paddy husk; with 10 $\%$ moisture content is around 20 . The quantity of ash formation in this particular furnace (test) is around $25 \%$ (Ref. 3.3).Therefore, by comparing the above figures, it would say that there is no much waste of heat during the combustion of paddy husk and the barn combustion efficiency is in an acceptable level.

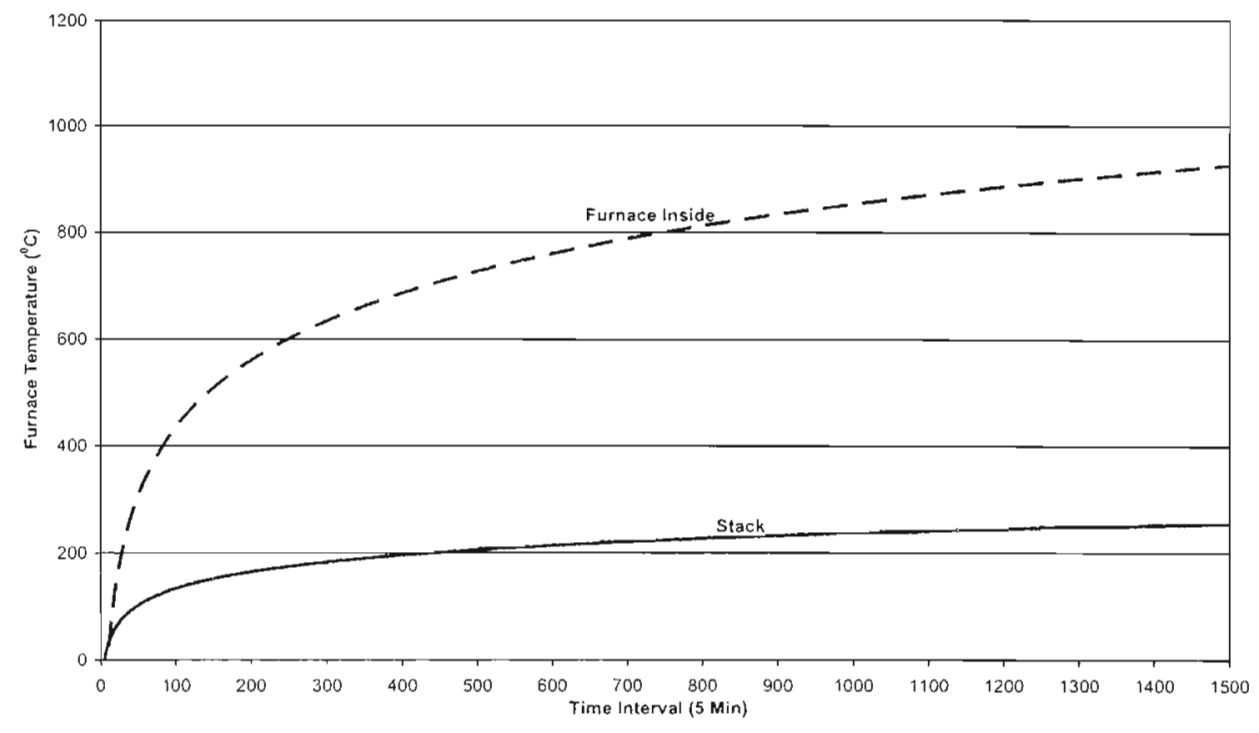

Fig. 06 - Average Temperature Variations in the Stack \& Furnace Inside 


$\begin{array}{ll}\text { Calorific Value of Paddy Husk } & =15.2 \mathrm{MJ} / \mathrm{kg} \\ \text { Paddy Husk Moisture Content } & =10 \% \\ \text { Total Paddy Husk Consumption } & =3987 \mathrm{~kg} \\ & =60602 \mathrm{MJ} \\ \text { Total Heat Content } & =20 \% \\ \text { Total (Unburnt + Ash) Generating }=997 \mathrm{~kg} \\ \text { Theoretical Ash Content } & =199 \mathrm{~kg} \\ \text { Total Unburnt Paddy Husk } & =3030 \mathrm{MJ} \\ \text { Waste Heat (With the Ash) } & =57572 \mathrm{MJ} \\ \text { Energy Taken to the Barn } & =95 \% \\ \text { Furnace Efficiency } & \end{array}$

\subsection{Overall Efficiency of the Barn}

The overall efficiency of the barn is calculated based on the heat taken by the moisture to cured leaf. The estimated values using the particular tested batch data are given below.

$\begin{array}{ll}\text { Weight of the Green Leaf } & =3,500 \mathrm{~kg} \\ \text { Weight of the Cured Leaf } & =525 \mathrm{~kg} \\ \text { Moisture Removed } & =2,975 \mathrm{~kg} \\ \text { Heat Required to Remove Moisture }=7,810 \mathrm{M} \text { J } & =49,239 \mathrm{MJ} \\ \text { Heat Input to the Barn } & =16 \% \\ \text { Overall efficiency of the barn } & =16\end{array}$

\subsection{Modifications, Improvements and Recommendations}

Since all the items and techniques that have been used in this industry are ancient, the identified potential improvements could take place.

\subsection{Barn Modifications and Barn Walls Improvements}

Even though there is no considerable heat losses through the stack, curing process requires high amount of paddy husk. This understood that considerable amount of heat is absorbed by the barn walls. Because this barn walls were constructed out of engineering bricks or cement blocks and those materials have high capability of heat absorption. Also blow holes and propagation cracks on the walls absorb considerable amount of heat. This is mainly due to incomplete (not final finishing) walls of the barns.

Therefore the heat losses through walls can be reduced by applying an insulated material layer inside the wall surfaces.

\subsubsection{Barn Floor}

There was no any barn inside floor modifications and it is remaining as natural floor. The soil is also a heat absorbing material like bricks and therefore as such considerable amount of heat can be absorbed by the barn floor. This is mainly due to the radiation heat emitted from the bottom surface of the ducting which is directly in contact with the floor, since the ducting system is laied closed to the barn floor level.

Therefore the heat loss due to floor absorption can be reduced by applying heat reflective material layer over the floor. Before that the floor has to be leveled properly and cemented.

\subsubsection{Barn Floor}

There was no any barn inside floor modifications and it is remaining as natural floor. The soil is also a heat absorbing material like bricks and therefore as such considerable amount of heat can be absorbed by the barn floor. This is mainly due to the radiation heat emitted from the bottom surface of the ducting which is directly in contact with the floor, since the ducting system is laied closed to the barn floor level.

Therefore the heat loss due to floor absorption can be reduced by applying heat reflective material layer over the floor. Before that the floor has to be properly leveled and cemented.

\subsubsection{Air Ventilation Controlling}

The barn has several openings (air vents) on walls and roof top in order to control the humidity level. Wider the vent opening more the thermal energy waste. Therefore it is necessary to control the vent opening according to the temperature inside the barn.

A proper vent controlling system is required to control the heat flow. This system should have to be sensed the inside temperature of the barn.

\subsubsection{Door Sealing}

The tested barn door was not properly sealed and therefore the heat leakages had take place. Also this door was made out of GI sheets and was not insulated.

It is necessary to make on air tight door and apply insulated material layer on the inside surface of the door. 


\subsubsection{Barn Loading System}

As discussed under the sub titles 2.1 and 3. 1, the barn is tightly packed while loading and therefore there is no any space or path for flowing heat as well as removing moisture. Due to these disturbances, curing product is uneven and curing process is slow. (Reference Fig. 01 and Fig. 06) This can be easily overcome by putting spaces between tobacco leaves hanging poles while loading. This method can not be practically done to the present system and a simple modification has to be added to the leaves hanging cross bars as described below.

Fix the size of $6^{\prime \prime}$ long and $2^{\prime \prime}$ height wooden web pieces on the top surface of cross bars with $2^{\prime}$ length intervals. This web piece has to be fixed according to the "Zig Zag" ("Z") pattern in each layer. Then the tobacco hanging poles can not be pulled towards; while loading, due to these wooden pieces. Fig. 07 illustrates the wooden web fixing details.

\subsubsection{Heat Transfer Ducting System}

The present available ducting system is discussed under the sub title 4.1.Replacement of the ducting system in every two seasons require an additional cost to the curing process. In the present system, the ducting system has to be disassembled and reassembled after each curing process. The main purpose of this is to remove fly ash collected in the ducts. Therefore due to this repetition the ducting system would be damaged. (Mainly the circular shape becomes an irregular and difficult to reassemble the adjacent parts). If there is any method to remove fly ash collect in the duct, the ducting system can be permanently fixed.

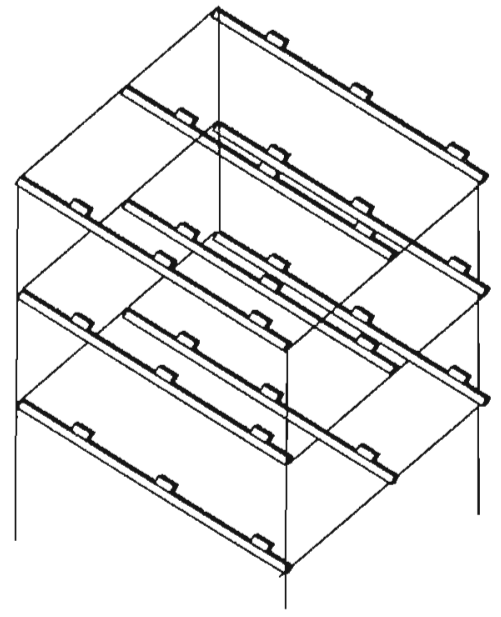

Fig. 07 - Wooden Web Fixing Details to Cross Bars
The fly ash collected can be removed without dissembling the ducting system by introducing 2" diameter cleaning ports (possibility to plug while curing) on the bottom side of the ducting system. An additional air blower woill require to apply pressure raised air after ench curing process. Permanent fixing of the ducting system can reduce the ducting cost.

Clay is used as a present sealing material after reassembling the ducting system. The perfect sealing could not be achieved (not bonded with the GI ducting) and also the thermal cracks could be formed at duct joints. Therefore fly ash and un burnt carbon particles can be emitted to the barn. These emitting particles will react with the cured leaves and as a result the quality of leaves is changed.

Proper sealing of ducting avoids the particulate contaminants with the tobacco leaves and obtain good quality products.

\subsubsection{Changing the Arrangement of Ducting System}

In the present system, the high temperature heat is carried in a single duct; from the furnace to the end of the barn, and then distributed to both sides of the barn via two ducts. If there is a possibility to distribute high temperature heat; just after the cast iron pipe, to both sides of the barn, the heat transfer due to radiation can be increased. As a result of dividing this high temperature heat to both sides, there would not be over heating at adjacent tobacco leaves.

The heat distribution pattern can be improved by readjusting the present ducting system as in the Fig. 08 (a) and Fig. 08 (b).

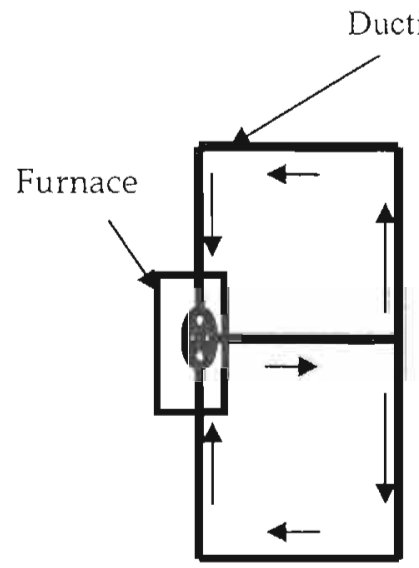

Fig. 08 (a) - Sketch of Present Heat Flow Arrangement 


\subsection{Furnace}

The present paddy husk burning system is discussed and illustrated in sub title 2.2. The methods of furnace improvements are discussed in this section.

In the case of combustion process, proper ventilation is required for a complete combustion. But this type of furnace has large amount of un-burnt paddy husk and this is mainly due to lack of ventilation to the furnace and an uneven paddy husk charging rate. The furnace efficiency can be improved by controlling these two parameters.

6.2.1 Improvement of Ventilation to the Furnace

In the present system, the bottom part of the furnace (i.e. almost $1 / 3$ rd of the furnace) is located just below the ground level and therefore poor ventilation takes place. The main reason is due to the heat transferring duct is laid closed to the ground level and it has tapped 1/3rd height from the furnace bottom. Fig. 09 (a) and Fig. 09 (b) illustrate the sketches of present and proposed furnace layouts.

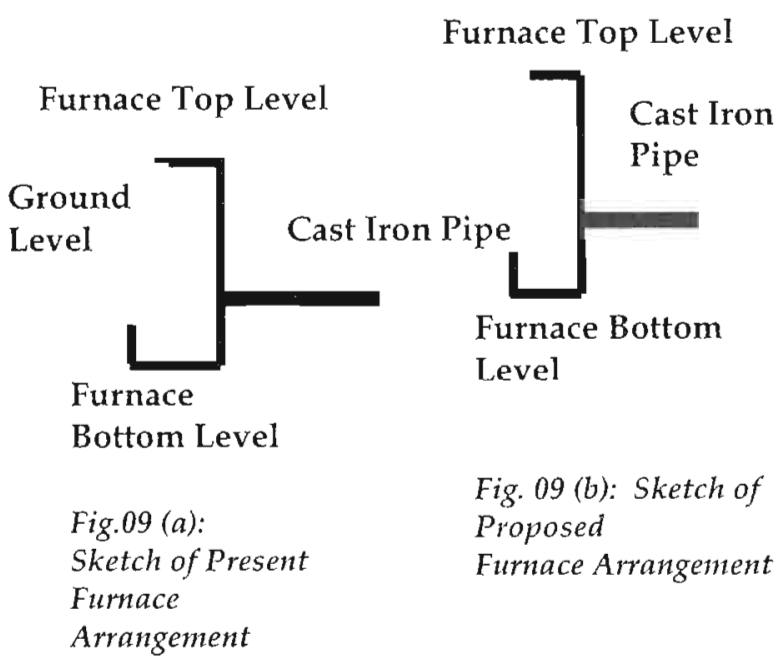

This can be avoided by placing the cast iron pipe at a distance some what higher than the present level and re constructing the furnace not beyond the ground level.

\subsubsection{Re adjusting the Grater Plates}

In the present grater system, 12 to 14 number of grater plates are used. The vertical space between two plates is about $2^{\prime \prime}$ and those plates are horizontally offset about $1.5^{\prime \prime}$. Those spaces are provided to supply required air for combustion. But the spaces between the plates may not be the optimal levels. Therefore it is necessary to do several trial tests; by adjusting the grater plates in both directions, in order to find out the optimum distances. Fig. 10 shows the arrangement of readjusting grater plates which can be used easily.

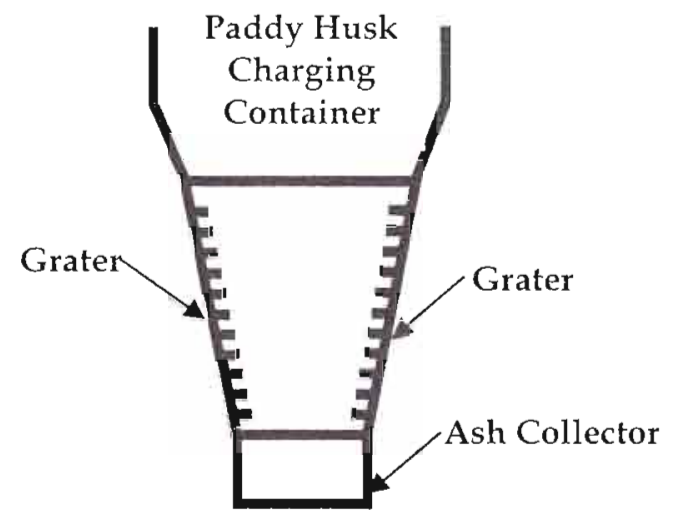

Fig. 10-Arrangement of Readjusting Grater Plates

\subsubsection{Paddy Husk Charging System}

At present, paddy husk charging to the furnace is done manually. Therefore the flame in the hearth can not be maintained uniform and as a result the pattern of heat produce is not uniform. Also the barn operator's attention is always required to maintain the required heating level.

The uniform heat level can be maintained by introducing continuous paddy husk charging system. The feeding system can be controlled by sensing the barn inside temperature.

\subsection{System Automation}

There are several openings available in the barn in order to remove generating moisture inside the barn. At present those openings are controlled manually according to the barn inside temperature and the performance of curing leaves. If the system can be automated to control those openings; by sensing the barn inside temperature and humidity, this would be eliminated to escape useful energy via the openings. However a simple understanding system should have to be introduced, since most of the barns are operated by uneducated persons. 


\subsection{Hot Water System}

The hot water distributing system can be introduced instead of the hot air ducting system in order to obtain required thermal energy.

This system would consists of water boiling container, hot water feed pump, radiators \& blowers and necessary hot water distributing piping. The similar system is used in rice mills for paddy drying process.

The above mentioned items will increase the capital cost. Even though the paddy husk can be used as a fuel to boil water; conșiderable electrical energy is required to operate the other drive components. Therefore the running cost can also be increased. However the quality of the cured, leaves can be improved with this system

\subsection{Conclusions}

7.1 The uniform temperature variations inside the barn can be achieved after simple modifications to the barn and furnace. Such as internal wall insulating, ducts improvement, leakage avoidance etc. These improvements can be done by the barn owners without a high capital investment. Finally the curing time can be reduced up to 3 to 4 days and this will affect to reduce paddy husk combustion.

7.2 The furnace modifications; such as grater plates adjustment, hot air ducting re arrangement etc. will help to achieve the optimal combustion conditions and initially those modifications have to be applied to the deport centers curing barns.

7.3 The final discussed methods; system automation, hot water system etc. to be initiated by the large scale manufactures.

7.4 Any methods discussed in this paper wil] help to reduce the heat losses and therefore will cause to reduce curing time and paddy husk consumption. Finally the curing cost will be reduced.

\section{Acknowledgement}

The authors are highly acknowledged Mr. Intage Kareem; former area manager in Galewela tobacco deport centre, for his fullest cooperation forwarded to success this study.
Further they appreciated the supportive staff in Galewela leaves collecting deports and other united tobacco processing plant officers for sharing their valuable experiences with me to success this work

\section{References}

1. Energy Audit Report in Energy \& Environmental Management Centre, Study on Tobacco Barns at Ceylon Tobacco Depot, Galewela-E\&EMC/MIS-208$718 / 2006-2006$.

2. Osborn Peter D, Handbook of Energy Data

\& Calculations, Butterworth, London-1985.

3. Jaluria Yogesh, Natural Convection Heat \& Mass Transfer, Pergamon, Oxford-1980. 